\title{
The Mental Health Care Act No 17 - South Africa. Trials and triumphs: 2002-2012
}

\author{
S Ramlall \\ Department of Psychiatry, University of Kwa Zulu Natal, Durban, South Africa
}

\begin{abstract}
The Mental Health Care Act 17 of $2002(\mathrm{MHCA})$ was promulgated in 2004. It has been hailed as one of the most progressive pieces of mental health legislation. A true measure of its merit is the degree to which it has transformed mental health services and in particular improved the quality of care. This paper will describe the impact of the Act on mental health care service delivery in the country. Literature pertaining to the MHCA published from 2006-2012, a report compiled by the South African Society of Psychiatrists and the results of a national survey conducted among Heads of Departments of Psychiatry, Mental Health Review Boards and Provincial Directors of Mental Health was reviewed. The MHCA has been successful in shifting the emphasis of care from psychiatric institutions to general hospitals. However, the integration of services has been hampered by infrastructure constraints and shortages of mental health personnel. It has been less successful in integrating mental health care into primary health services where the focus remains largely on the pharmacological maintenance treatment of the chronically mentally ill. Little attention has been given to the health promotion, disease prevention and rehabilitation aspects of care. Mental health review boards contend with limited resources, administrative challenges and limited political support. Isolated pockets of success characterised the implementation of the MHCA across the country. Greater investment of resources is needed to ensure the comprehensive implementation of the Act.
\end{abstract}

Keywords: Mental Health Care Act; implementation; mental health service delivery; South Africa

Received: 25-06-2012

Accepted: 24-07-2012

doi: http://dx.doi.org/10.4314/ajpsy.v15i6.49

This article is based on a paper presented at the National Mental Health Summit convened by the Department of Health, Republic of South Africa from 12-13 April 2012.

\section{Introduction}

South Africa was lauded in 1994 for peacefully dismantling the shackles of an apartheid system that discriminated against people on the basis of race. Ten years later, in 2004, the new democracy promulgated the Mental Health Care Act 17 of $2002(\mathrm{MHCA})^{1}$ which sought to dismantle the apartheid practices that existed within a health care system that discriminated against those with mental illness. The implementation of the MHCA speaks to the political as well

\section{Correspondence}

Dr S Ramlall

P.O. Box 65810, Reservoir Hills, Durban, 4090, South Africa

email: ramlalls4@ukzn.ac.za as moral obligations of a government toward all of its citizens in creating a legislative framework for mental health services as well as ensuring the successful implementation thereof. Eighteen years into our democracy, it is anticipated that the first National Mental Health Summit will advance the cause of mental health services in our country.

In measuring the impact of the new legislation upon the mental health landscape of our country, cognisance must be taken of identified shortcomings that pre-dated the MHCA's implementation. A policy-orientated workshop held in 1993 identified the following prevalent challenges:

.fragmentation, lack of inter-sectoral collaboration, lack of co-ordination of funding, inaccessibility of services in both urban and rural areas, inadequate emphasis on psycho-social problems, almost no prevention and promotion or early identification of problems, too much emphasis on institutional care, shortage of mental health workers and too much emphasis on one-to-one care at the expense of groups and community care. "2 
The MHCA has been hailed as being one of the most progressive in the world in its legislating of human rights for the mentally ill. A critical word in the Act's title is "care"-this must be our guiding ethos. ${ }^{3}$ To what extent has it succeeded in improving the quality of care of the mentally ill?

\section{Evaluation}

Three main sources of information were used to evaluate the impact of the Act:

\section{Published literature:}

17 relevant publications from February 2006-February 2012.

\section{Surveys:}

2 surveys of opinion and experience conducted countrywide i.e.: A report compiled by the South African Society of Psychiatrists (SASOP) (Unpublished, 2011) and a survey of academic heads of departments of psychiatry, provincial directors of mental health as well as chairpersons of Review Boards conducted in March 2012; information was received from 6 of 9 Provinces.

\section{Anecdotal evidence:}

This is based on experiences of implementation at a provincial level.

It is acknowledged that vast discrepancies exist in resources and services between and within provinces ${ }^{4}$ which cannot be adequately captured in this paper.

\section{Triumphs and trials \\ Clinical}

The Act tasks every organ of state responsible for health to implement the Act to ensure that mental health services are provided equitably and efficiently yet no provision was made for how this is to be achieved. Implementation of the Act has been haphazard and dominated by acute care with neglect of the promotion, prevention and rehabilitation components of care.

\section{Community based care}

Historically mental health services revolved around large mental institutions, stand-alone clinics and an emphasis on psychopharmacological care. A comprehensive, integrated, co-ordinated community-based mental health service at all levels was proposed in $1997^{5}$ and incorporated into the MHCA. The enforced integration of mental health into the general health system has been a welcome move that promotes de-stigmatization. Eighty-three percent of hospitals surveyed in KwaZulu Natal reported that the Act had improved mental health care through the protection of rights, the provision of least restrictive care and reduction of discrimination. ${ }^{6}$ Isolated reports from other provinces confirmed that accessibility of mental health services and quality of care had been enhanced. However, integration appears to have been focussed largely at district and regional hospital level to the neglect of community and Primary Health Care (PHC) services. Further, despite a prevalence of $16.5 \%$ per annum of common mental disorders in our country ${ }^{7}$, the implementation of the Act appears to have focused clinical attention predominantly on the severely mentally ill and emergency psychiatry. 6,8 This is contrary to the optimal mix of services recommended by the $\mathrm{WHO}^{9}$ which highlights that the greatest quantity and frequency of need is at the community level where services are the least expensive. A review of community psychiatric services in Southern Gauteng, revealed that primary health clinicians played no active role in the management of the mentally ill with care being supplied mainly by mental health professionals. Psychopharmacological treatment was the sole modality of treatment at the majority of clinics and where multi-disciplinary team members were present, only $0.2 \%$ of users had access to them. Insufficient numbers of community clinics failed to meet the local needs or fulfil the basic principles of community psychiatry as well as legislative and policy requirements. ${ }^{10}$

In the North West province ${ }^{11}$ general satisfaction was reported by patients and staff with the following crucial areas highlighted as requiring attention: human and physical resource constraints, specialised and individualised mental health services vs integration into 'supermarket' services, training needs, negative attitudes towards mental health and a lack of teamwork, integration and co-ordination. The need for active political support, managerial support and the provision of the necessary resources were also identified as being critical to the success of the implementation of the Act. ${ }^{11}$ In KZN, it was noted that 'decentralized' mental health services translated largely to the provision of emergency psychiatry and the provision of medication to stable, chronically-ill patients. The researchers called for an injection of mental health resources into the Primary Health Care ( $\mathrm{PHC}$ ) package and more efficient use of existing resources. ${ }^{8}$ These findings suggest that the much-needed transformation of community psychiatric services has not materialised.

\section{Access and integration into general health}

A review of involuntary applications to a Gauteng Mental Health Review Board (MHRB) in 2008 confirmed that significant progress had been made in this regard. The need for massive education of public and professionals, and financial investment by the Department of Health (DOH) to improve human resources and infrastructure was reiterated. ${ }^{12}$ The call for greater assistance with implementation ${ }^{6}$ has been echoed across the country, with the following identified challenges impeding optimum service delivery: lack of proper facilities, bed shortages, staff shortages (Nurses, Psychiatrists, Occupational Therapists, Social Workers, Psychologists), challenges relating to the MHCA forms, availability of psychotropic medication, difficulties with the South African Police Services(SAPS), and problems with MHRBs which ranged from them being non-functional to dysfunctional and included fractious relations between Board members and health professionals.

\section{Resource constraints}

'Wherever you go, demand exceeds capacity'13 and successful implementation hinges on the systematic addressing of the lack of resources. ${ }^{14}$ The call for a 'substantial injection of financial and human resources' 15 to 
support the implementation of the MHCA has been a common plea. The median percentage of health expenditures dedicated to mental health is $0.5 \%$ in low income countries and 5.1\% in high income countries ${ }^{16}$ and in $\mathrm{KZN}$ the figure is $0.03 \%$-a figure that had not increased over a 10 year period spanning the implementation of the Act. ${ }^{6}$ In KZN, a mean increase of $10.2 \%$ per annum in budget allocations was made to general hospitals as opposed to $3.8 \%$ to public psychiatric hospitals over the same period; in addition, four out of six psychiatric but no general hospitals saw a reduction in their allocations. ${ }^{17}$ Such discriminatory practices portend a poor prognosis for mental health in our country.

The integration of mental health into general health has precipitated an infrastructure crisis with respect to a shortage of both acute and chronic beds throughout the country, undermining the successful implementation of the Act. KZN has been reported to have $25 \%$ of the acute mental health beds required to comply with national norms. ${ }^{17}$ The implementation of the Act without due consideration being given to the infrastructure requirements resulted in hospitals being left to manage potentially dangerous patients in sub-optimum clinical environments: More than sixty percent of hospitals did not have adequate facilities to fulfil the legislative requirements 41.7\% admitted Mental Health Care Users (MHCU) to general medical or surgical wards and only $27.8 \%$ had a dedicated psychiatric unit. Common complaints related to the lack of sufficient beds, seclusion rooms and staff to accommodate the clinical demand and the challenges of managing disruptive patients in a general hospital setting. The lack of seclusion facilities posed another major challenge with more than half (55.6\%) of designated hospitals having no seclusion facility. Those with seclusion facilities were dissatisfied with the infrastructure or the number of facilities, with five hospitals using inadequately refurbished wards or medical isolation units as 'seclusion' facilities. ${ }^{6}$

Similar challenges were echoed by practitioners surveyed from around the country who identified overcrowding in specialized hospitals, the use of old and dilapidated buildings, the lack of suitable facilities for MHCUs in general hospitals, the shortage of beds, acute admission wards that posed serious health and safety hazards, the inability to separate male and female patients and the lack of seclusion facilities rooms as ongoing challenges that compromised their ability to honour the standards and values enshrined in the Act.

A quantitative and qualitative shortage of human resources is also stifling service provision countrywide. KZN has 25\% of psychiatrists required by norms ${ }^{17}$, and $70 \%$ of its hospitals did not have the necessary medical or nursing staff to provide an adequate service. ${ }^{6}$

A recent survey revealed that workplace stress, just one indicator of the mental ill-health of our nation, costs SA about R3-billion a year. ${ }^{18}$ Mental illness existed long before the scourges of leprosy, syphilis, herpes, Tuberculosis and HIV and it's social, economic and health burden threatens to surpass the ravages wrought by the HIV/AIDS pandemic! Unfortunately it has not enjoyed commensurate political and economic backing.

\section{Administration}

The least popular and most controversial aspect of the Act has been its administrative burden. The mountain of paperwork involved has challenged the administrative capacity of most hospitals that are unable to manage the paper trail. Forty four percent of hospitals were not forwarding their forms to the MHRB. ${ }^{6}$ A proposal for a comprehensive revision of the forms has been submitted by the South African Society of Psychiatrists (SASOP) and implementation of the changes is pending.

\section{Mental Health Review Boards}

MHRBs have been designated to provide a 'critical and legally-specified role'19 to guide and support the hospitals and protect the rights of MHCUs by investigating abuse, neglect and exploitation. ${ }^{1}$ They are ideally and strategically placed between consumers and clinicians as well as the Health Ministry and Judiciary to advocate for mental health as well. ${ }^{6}$ With the exception of the experience of the 'trendsetting' Western Cape MHRB, MHRBs generally labour under the challenges of budgetary constraints, poor administrative and political support, a lack of basic resources to conduct business as well as the challenges and limitations of the services that they are tasked to oversee. Procedurally they are expected to report directly to their provincial health ministers who refuse to meet with them. Activity levels vary with $80 \%$ of KZN hospitals not having had a single visit in a 6 month period. MHRBs were generally perceived as being unhelpful in addressing practical issues, difficult to communicate with and lacking power to meaningfully contribute to transformation of neglected services. ${ }^{6}$ Problems pertaining to poor clinician-review board relations ('obstructive and dismissive of clinicians'), remuneration, training, supervision and professional boundaries of MHRB members were highlighted. The limited powers accorded to the Board rendered them ineffective in summoning investigations in cases of abuse and exploitation. Despite these challenges, reports of well-functioning boards, committed to championing mental health and taking initiatives to promote and advocate for mental health bear testimony to their potential to fulfil their legislated responsibility if they were appropriately supported and resourced.

\section{Human rights violations}

The Act dedicates an entire chapter to the rights and duties pertaining to the Mental Health Care User (MHCU). Major criticism of previous legislation has been the 'paternalistic' attitude towards users. Involuntary detention processes draw much criticism and human resource and infrastructure constraints at institutions threaten to violate the very rights that the MHCA seeks to uphold. ${ }^{20}$ Users perceive that their rights are infringed upon during acute episodes of illness with methods of containment often seen as punitive rather than therapeutic. ${ }^{21}$ "There are laws, regulations, principles and ethical codes....The tragedy is lack of implementation, compliance, enforcement and oversight bodies to ensure that these benefit mental health care users."22 An exception appears to be the Western Cape MHRB which reported a 'quantum leap forward all round' in users' and providers' knowledge of the Act. ${ }^{13}$

The media has highlighted appalling conditions that exist 
at certain psychiatric institutions and the Act has been a stimulus for change at several hospitals around the country such as Fort Napier Hospital in KwaZulu-Natal, the Libode Mental Health facility (Eastern Cape) and George Mukhari Hospital (Garankuwa). While these measures are welcomed, infrastructure at most mental institutions countrywide remains in dire need of improvement.

\section{Conclusion}

Progress following the 1993 evaluation $^{2}$ is evident with respect to the integration of mental health services into the general health system, albeit only at hospital level. The Act has increased the accessibility of care, yet hospitals face numerous challenges in meeting the legislative mandate.

South Africa can be proud of being one of less than $40 \%$ of countries worldwide that has mental health legislation that has been passed after 199023, but this accomplishment is overshadowed by the absence of a supporting implementation plan. It has been wisely stated that 'policy without an implementation plan is not worth the paper it is written on'24, and it is therefore against the yardstick of implementation that the success of the Act has been measured.

This review of the state of implementation of the Act identifies isolated pockets of success which mirror the socioeconomic landscape of our country. Legislation by itself is not adequate to bring about the major reform required for the South African mental health system. ${ }^{4}$ Issues of resource allocation, mental health policy, quality assurance and information systems still need to be addressed. The lack of a funded implementation plan is evidence of the low priority accorded to mental health. This shortcoming has been acknowledged by the National Department as evidenced in the words of the previous Deputy Minister of Health: "The Act goes a long way towards improving the human rights of people with mental illness and intellectual disability, however it is only in the successful implementation of the law, including proficient Review Boards that these rights will become concrete reality for people". ${ }^{19}$

Steps to address this oversight are yet to be initiated. It is acknowledged that sufficient political will is necessary to improve availability of and access to humane mental health care. ${ }^{25}$ A political commitment from government to dedicate a budget and drive the implementation of the ideals enshrined in our Act will ensure that the vision captured in the MHCA 17 of 2002 becomes a reality for all.

\section{References}

1. National Department of Health. No. 17 of 2002: Mental Health Care Act,2002. Cape Town Government Gazette, 2002:79.

2. Freeman M, Pillay Y. Mental Health Policy-Plans and Funding. In: Foster D, Freeman M, Pillay Y, editors. Mental health policy issues for South Africa, 1997.

3. Szabo CP. The Mental Health Care Act: challenges and opportunities. South African Psychiatry Review 2006;9:1-5.

4. Lund C, Kleintjes S, Campbell-Hall V, Mjadu S, Petersen I, Bhana A, et al. Mental Health policy development and implementation in South Africa: a situational analysis. Phase 1. Country Report. Cape Town: Mental Health and Poverty Project, 2008.

5. Department of Health. White paper for the transformation of the health system in South Africa. In: National Department of Health, editor. Pretoria, 1997

6. Ramlall S, Chipps J, Mars M. Impact of the South African Mental Health Care Act No. 17 of 2002 on regional and district hospitals designated for mental health care in KwaZulu-Natal. South African Medical Journal 2010;100(10):667-70.

7. Williams DR, Herman A, Stein DJ, Heeringa SG, Jackson PB, Moomal H, et al. Twelve-month mental disorders in South Africa: prevalence, service use and demographic correlates in the population-based South African Stress and Health Study. Psychological Medicine 2008;38(2):211-20.

8. Petersen I, Bhana A, Campbell-Hall V, Mjadu S, Lund C, Kleintjies $S$, et al. Planning for district mental health services in South Africa: a situational analysis of a rural district site. Health Policy and Planning 2009;24(2):140-50.

9. World Health Organization. The optimal mix of services for mental health. Mental health policy, planning and service development. Geneva: WHO, 2003.

10. Moosa MYH, Jeena FY. Community psychiatry: An audit of the services in southern Gauteng. South African Journal of Psychiatry 2008; 14(2):36-43.

11. van Deventer C, Couper I, Wright A, Tumbo J, Kyeyune C. Evaluation of primary mental health care in North Western province- a qualitative view. South African Journal of Psychiatry 2008; 14(4):136-40.

12. Moosa MYH, Jeena FY. A review of the applications for involuntary admissions made to the Mental Health Review Boards by institutions in Gauteng in 2008. South African Journal of Psychiatry 2010;16(4):125-30.

13. Bateman C. Dismal use of legal safety net for mental health patients. South African Medical Journal 2012;102(2):5569.

14. Lund C, Stein DJ, Flisher AJ, Mehtar S. Challenges faced by South African health services in implementing the Mental Health Care Act. South African Medical Journal 2007;97(5):352-3.

15. Jonsson G, Moosa MYH, Jeena FY. The Mental Health Care Act: Stakeholder compliance with Section 40 of the Act. South African Journal of Psychiatry 2009; 15(2):37-42.

16. World Health Organization. Mental Health Atlas 2011, 2011.

17. Burns JK. Mental health services funding and development in KwaZulu-Natal: a tale of inequity and neglect. South African Medical Journal 2010;100(10):662-6.

18. Roberts J. Stress at the workplace costs SA billions. Sowetan Live. Johannesburg, 2012.

19. Department of Health. Mental Health Review Board Orientation Guideline and Training Manual. In: Health, editor. Pretoria, 2007.

20. Moosa MYH, Jeena FY. Involuntary treatment of psychiatric patients in South Africa. African Journal of Psychiatry 2008; May: 109-12.

21. Mayers P. Mental Health Service Users' Perceptions and Experiences of Sedation, Seclusion and Restraint. International Journal of Social Psychiatry 2010;56(1):60-73.

22. Mkize DL. Human rights abuses at a psychiatric hospital in KwaZulu-Natal. South African Journal of Psychiatry 2007;13(4):137-42.

23. World Health Organization. Mental Health Legislation and Human Rights. Singapore: World Health Organization, 2003.

24. Sweet M. Australian state and federal governments are attacked on mental health care. British Medical Journal 2005;331:984.

25. Saraceno B, Van Ommeren M, Batniji R, Cohen A, Gureje O, Mahoney J, et al. Barriers to the improvement of mental health services in low-income and middle-income countries. Lancet 2007;370(9593):1 1 64-74 